\title{
Insulation Performance Analysis of Field Aged and New MV XLPE Cables Using Various Diagnostic Techniques
}

\author{
Yousef Al-Onazi ${ }^{1,}$ *, Nissar Wani $^{1}$, Abdulrahman Al-Arainy ${ }^{1}$, and Yasin Khan $^{1}$ \\ ${ }^{1}$ Department of Electrical Engineering, King Saud University, Riyadh, Saudi Arabia
}

\begin{abstract}
Cross-linked polyethylene (XLPE) cables are widely used in the distribution and transmission networks of power systems. The insulation materials of these cables are stressed by the over voltages and are also exposed to various environmental conditions. This leads the power cables to degrade during their normal life span. Therefore, it would be advantageous for the power utilities to acquire the cable's insulation condition frequently during their operation. In this paper, experimental studies were carried out on short sections of field aged as well as un-aged medium voltage (MV) XLPE cables to investigate the insulation condition using non-destructive diagnostic techniques such as Dissipation Factor (DF), Isothermal Relaxation Current (IRC), and Partial Discharge (PD) characteristics at 60Hz. From this set of experiments, different parameters will be used to analyze the dielectric response and the insulation condition. Finally, the results show how the VLF dissipation factor works efficiently to assess cable aging.
\end{abstract}

\section{Introduction}

Cross-linked polyethylene (XLPE) is the commonly used polymeric insulation in electrical networks. It has lower electrical losses with non-polar dielectric material with high resistivity and low electric permittivity [1]. These properties make the insulation with a low dielectric loss and making it more economical for the long run. However, during the operating service, the insulation materials of the XLPE cables are continuously subjected to electrical, thermal, mechanical, and environmental stresses which lead the cables to degrade their long-term operating life. Therefore, diagnostic tests are needed to evaluate the aging condition of the insulation in order to predict the cable's remaining useful life. In order to make decisions, the utilities need to determine the insulation condition with reliable diagnostic tools. This may need multiple techniques to provide full assessment in some cases to indicate about the bulk insulation and the local defects for insulation with terminations and joints. Recently several testing techniques have been developed such as Dissipation Factor (DF) with very low frequency (VLF) which can be used to describe the losses in the insulation material, online/offline Partial Discharge (PD) to indicate the detectable PDs for cable accessories and internal defects, and Isothermal Relaxation Current (IRC) to analyze the depolarization current of the insulation material. Furthermore, the change of the loss factor and the insulation parameters with the frequency variation to investigate the dielectric performance [2].

In this paper, several diagnostic techniques were carried out to characterize the electrical properties and therefore assess the insulation condition of new and aged XLPE cables.

\section{Experimental}

\subsection{Description of samples}

Two XLPE cables with a cross-section area of $630 \mathrm{~mm}^{2}$ and with a nominal voltage of $8.7 / 15 \mathrm{kV}$ were tested in the laboratory. One is an aged cable, which has been in service for 17 years with about 10-meter length while the other is a new cable with 15 -meter. Proper stress cone terminations were installed at both ends (terminals) in each XLPE cable to reduce the local electric stress at the points of termination.

\subsection{Setup of experiments}

The tests were performed with different conditions for the aged cable. Firstly, the cable was tested in dry condition after 17 years "in service", followed by one year after the de-energization at which the cable was stored in a dry place. The cable then tested three times after 60,120 , and 180 hours of aging in water with $2 \mathrm{U}_{0}$ applied AC voltage. Moreover, the cable was placed for around 1500 hours in a PVC tube filled with tap water while the outer jacket was removed to allow the water to ingress between the tap screen and the semiconductor layer in presence of humidity and electrical stress.

The VLF test is performed by applying voltage starting from $0.5 \mathrm{U}_{0}$ at $0.1 \mathrm{~Hz}$. If the cable is in good condition, then the voltage will be increased stepwise by $0.5 \mathrm{U}_{0}$ until reaching the higher voltage level of the test i.e., $2 \mathrm{U}_{0}$. The measuring system follows the conventional tangent-delta (TD) testing technique in accordance with IEEE 400.2 [3]. Moreover, the measuring system is

\footnotetext{
* Corresponding author: ygonazi@se.com.sa
} 
programmed to calculate the mean and the time stability in each step from 15 readings with 10 seconds measuring time for each reading. According to IEEE 400.2 [3], acceptance criteria for newly installed cables, TD should not exceed $1 \times 10^{-3}$ at $\mathrm{U}_{0}$. When the test voltage is increased from $1 \mathrm{U}_{0}$ to $2 \mathrm{U}_{0}$, the tip-up $\mathrm{TD}$ should not increase by more than $0.8 \times 10^{-3}$ and the stability at $\mathrm{U}_{0}$ should be less than $0.1 \times 10^{-3}$. Before the test was performed, the room temperature is recorded at $24^{\circ} \mathrm{C}$ (ambient temperature), while the pressure is 949 mbar.

In order to analyze, the dielectric response the measurements were carried out to determine the parallel (RC) model of the aged and the new XLPE insulators by measuring the change of the resistance (Rp), the capacitance $(\mathrm{Cp})$, and the tangent-delta with the variation of the voltage and the frequency. In general, the TD measurements are carried out by balancing the bridge circuit of the classical Schering bridge method. However, this method and its experimental set-up are not practical for field tests [4]. Therefore, digital measurement devices which provide mobile use and convenience in field studies are developed for TD measurements. In this experiment, the measurements are obtained by Midas $2880^{\circledR}$ mobile insulation diagnostic system.

The partial discharge (PD) activities of the aged cable were captured using DDX-7000 instrument with power frequency $60 \mathrm{~Hz}$ partial discharges conventional detection technique. The pulse readings have been calibrated in accordance with IEC 60270 [5], with a measured background noise level of $0.88 \mathrm{pC}$ before starting the test. The PD test was carried out to analyze the behavior of the PDs with voltage function in order to indicate the creation of electrical trees or any detectable voids from very small microcavities in the tested cable system [6]. PDs have distinguishable characteristics at different stages of the aging process which are typically characterized by their magnitude, pulses number per power cycle, phase-resolved PD patterns (PRDP), and dependence on the applied voltage [7].

Before performing the isothermal relaxation current (IRC) measurements, the new, as well as the aged cable, were properly grounded from both sides at the conductor and the tap screen for at least 4 hours to avoid electric charging that would remain within the cable because it might impact the polarization and depolarization measurements. Moreover, the insulation surface was cleaned to prevent the current leakage that relates to the unclean insulation surface [8]. The aged sample was stressed for $180 \mathrm{~h}$ in the water at $2 \mathrm{U}_{0}$ before performing the test to assure that the humidity will be concentrated inside the water tree structures if existed [9]. The preliminary condition of the measuring channels was measured for 30 seconds for both cables to determine the noise level before performing the test. The mean and standard deviation were obtained within the allowed range $20 \mathrm{pA}$ and $5 \mathrm{pA}$. The calculated values were within the accepted range with $16.74 \mathrm{pA}$ and $2.55 \mathrm{pA}$ for the new cable and $17.44 \mathrm{pA}$ and $2.64 \mathrm{pA}$ for the aged cable.

To investigate the polarization processes of the samples in the time domain, $1 \mathrm{kV}$ DC voltage is applied for a polarization time of 1800 seconds. Next, the DC voltage is removed and then the cable is short-circuited for 5 seconds. Finally, the depolarization current is measured for the same time period of 1800 seconds. The measured depolarization current or relaxation current has different types of traps depending on the trapped charges which can be approximated using a third-order time dependant exponential function according to [10].

\section{Results and discussion}

\subsection{Dissipation factor at VLF}

Figure 1 shows the tangent delta measurements for the new cable and the aged cable in different conditions with respect to the voltage $0.5 \mathrm{U}_{0}, 1.0 \mathrm{U}_{0}, 1.5 \mathrm{U}_{0}$, and $2.0 \mathrm{U}_{0}$ corresponding to $4.4 \mathrm{kV}, 8.7 \mathrm{kV}, 13.1 \mathrm{kV}$, and $17.4 \mathrm{kV}$. Based on the measurements, the determined TD values remain constant for all voltage levels in the un-aged (new) cable. All the repeated measurements give the same result which indicates that the cable insulation is in perfect condition. On the other hand, the aged cable gives higher values of the TD as the applied voltage is increased. Moreover, the mean values of the TD are slightly increased between $1 \mathrm{U}_{0}$ to $2 \mathrm{U}_{0}$, while in $0.5 \mathrm{U}_{0}$ the value of TD is higher as compared to $1 \mathrm{U}_{0}$ to $2 \mathrm{U}_{0}$. As compared to the IEEE criteria [3], the mean values of $\mathrm{U}_{0}$ are all much less than $4 \times 10^{-3}$ the allowed limit and the maximum tangent delta stability recorded values is $0.02 \times 10^{-3}$ which also far from the limit of the perfect insulation. Therefore, the TD values indicate low deterioration of the insulation. As a final comment, the results indicate normal TD values and no action required for both cables.

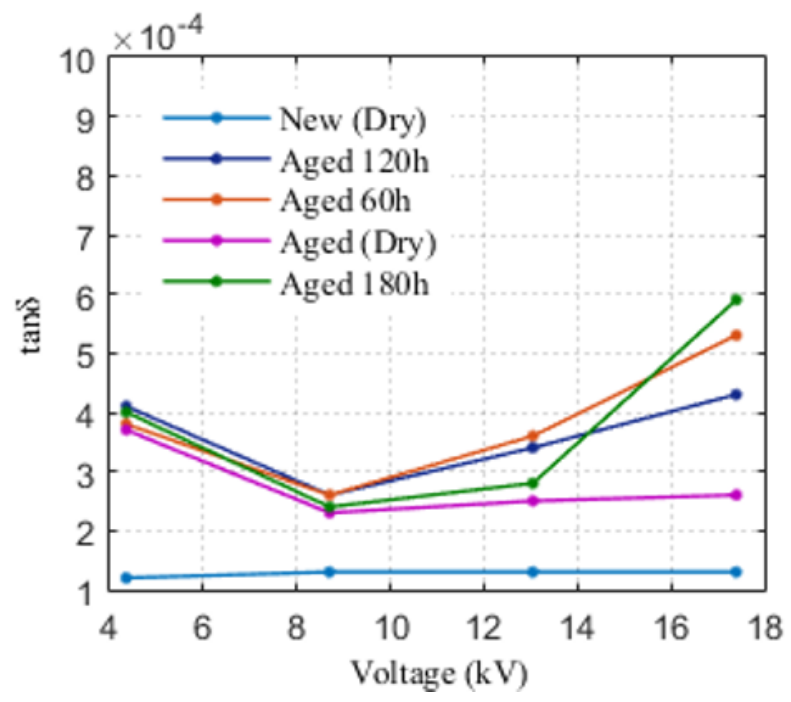

Fig. 1. VLF $0.1 \mathrm{~Hz}$ TD measurement $\left(0.5 \mathrm{U}_{0}\right.$ to $\left.2.0 \mathrm{U}_{0}\right)$.

\subsection{Dielectric response $(50 \mathrm{~Hz}-400 \mathrm{~Hz})$}

\subsubsection{Dissipation factor}

As shown in Figure 2 the TD values of the new and the aged cables are almost the same with minimum values obtained with 0.00025 at $50 \mathrm{~Hz}$. At higher frequency, the dielectric response of TD increases for the new cable. Whereas the TD value is less at its rated voltage $8.7 \mathrm{kV}$. 
The highest TD values at $4.4 \mathrm{kV}$ and $8.7 \mathrm{kV}$ for the new cable are observed at $400 \mathrm{~Hz}$ with 0.00058 and 0.00046 . While for the aged cable, the TD value decreases as the frequency increases and the TD is less at its rated voltage $8.7 \mathrm{kV}$. The highest TD values at $4.4 \mathrm{kV}$ and $8.7 \mathrm{kV}$ for the aged cable are observed between $100 \mathrm{~Hz}-150 \mathrm{~Hz}$ with 0.00028 and 0.00027 , respectively.

Similarly, when comparing the TD measurements at higher frequency $(50-400 \mathrm{~Hz})$ with those obtained at VLF $0.1 \mathrm{~Hz}$ in the previous section 3.1 , the TD shows the same behavior in increasing or decreasing nature. However, the TD values for $0.5 \mathrm{U}_{0}$ and $1.0 \mathrm{U}_{0}$ at $0.1 \mathrm{~Hz}$ are more than the values that obtained at higher frequency range due to the lower capacitive current and the inversely dependence of the frequency on the tangent-delta measurements [11].

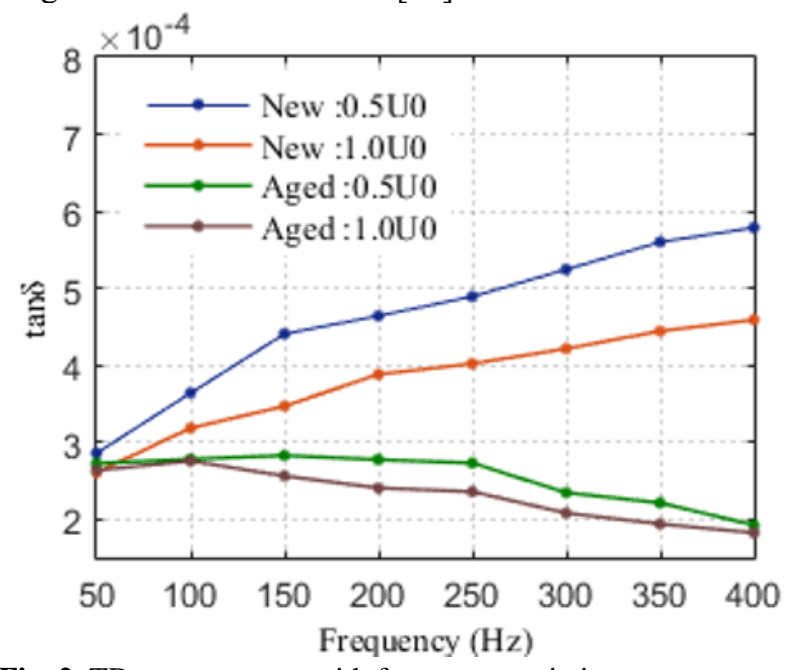

Fig. 2. TD measurement with frequency variation.

\subsubsection{Parallel resistance}

As shown in Figure 3 the insulation resistance (Rp) of the new and the aged cables decreases with increasing frequency. At higher frequency, the insulation reaches the minimum at $107 \mathrm{M} \Omega$ and $395 \mathrm{M} \Omega$, respectively. The highest resistance values were observed at $50 \mathrm{~Hz}$ with $1.25 \mathrm{G} \Omega$ and $1.82 \mathrm{G} \Omega$. Therefore, the resistance of the cable is highly influenced by frequency increment.

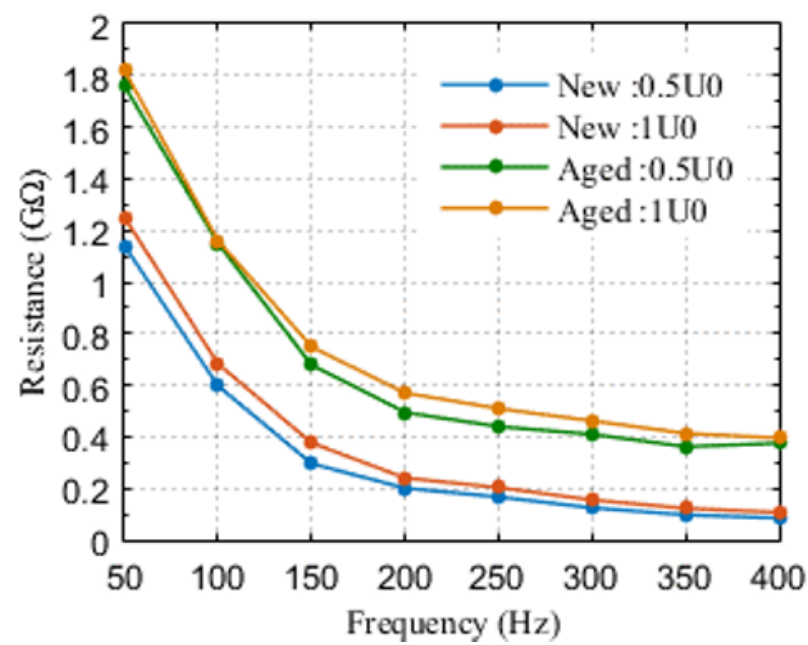

Fig. 3. Parallel resistance with frequency variation.

\subsubsection{Parallel capacitance}

The parallel capacitance $(\mathrm{Cp})$ values were measured at different frequencies with $4.4 \mathrm{kV}, 8.7 \mathrm{kV}$, and $13.1 \mathrm{kV}$. When the voltage is increased from $4.4 \mathrm{kV}$ to $13.1 \mathrm{kV}$, the capacitance remained relatively the same for the new and the aged cables with $8.14 \mathrm{nF}$ and $5.54 \mathrm{nF}$, respectively. Moreover, the same values were observed with the frequency range $50 \mathrm{~Hz}-400 \mathrm{~Hz}$. This response is typical for a new or non-defective cable [12].

\subsection{Partial discharge}

PD Measurements at $8.7 \mathrm{kV}$ were performed for the aged cable to ensure that the cable is free from PDs at $\mathrm{U}_{0}$. If the partial discharge inception voltage (PDIV) or the partial discharge extinction voltage (PDEV) is under the nominal voltage, then PD must be located [13]. The most important parameter is PDIV which determined by a stepwise or continuous increase of the applied voltage to the test object until the PD activities could be noticed. At this level, the voltage is measured to know if the cable is operating with permanent PD activity under normal service conditions or not. The measured PD level at $8.7 \mathrm{kV}$ was very low and equal to the background noise. Similar behavior was noticed above the nominal voltage up to $10.32 \mathrm{kV}$. As shown in Figure 4 the first PD activities were observed at $10.69 \mathrm{kV}$ PDIV level with an average discharge of $67.25 \mathrm{pC}$. At a lower voltage, the PDEV was measured at $9.43 \mathrm{kV}$ with an average discharge of $1.82 \mathrm{pC}$. Both PDIV and PDEV values with respect to the nominal voltage are greater than the $\mathrm{U}_{0}$, with $1.23 \mathrm{U}_{0}$ and $1.08 \mathrm{U}_{0}$, respectively. It clearly observed the cable normally operates at the nominal voltage $\left(\mathrm{U}_{0}\right)$ without any considered discharging activities unless during the transient voltage lightning or switching surges [14]. Therefore, direct actions are not required in this case. To test above PDIV level, the test was conducted at $1.73 \mathrm{U}_{0}$ corresponding to a $15 \mathrm{kV}$ peak. Figure 5 shows that as compared to the PDIV $10.69 \mathrm{kV}$, much more events have occurred at this voltage level. Furthermore, the maximum measured PD magnitude at $15 \mathrm{kV}$ is much more than the maximum magnitude of PDIV with $357 \mathrm{pC}$.

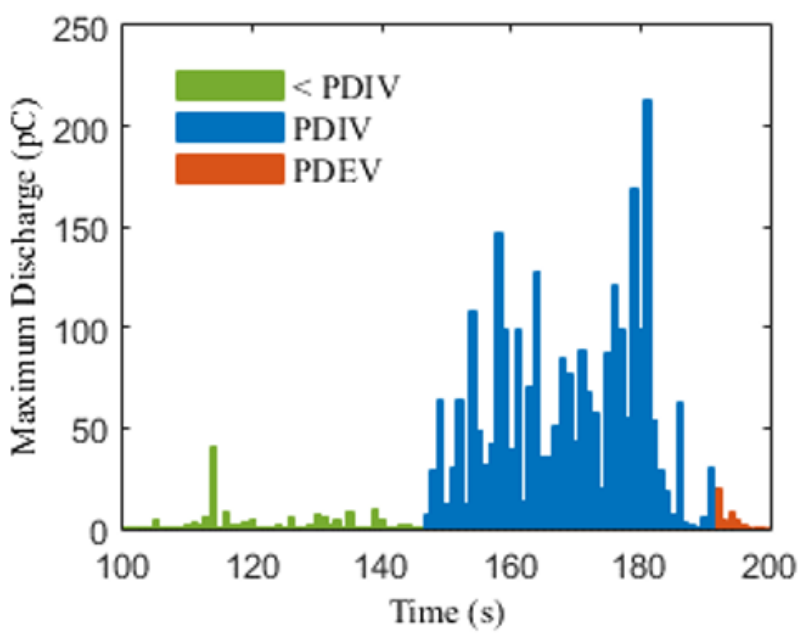

Fig. 4. PD magnitude with time at different voltages. 


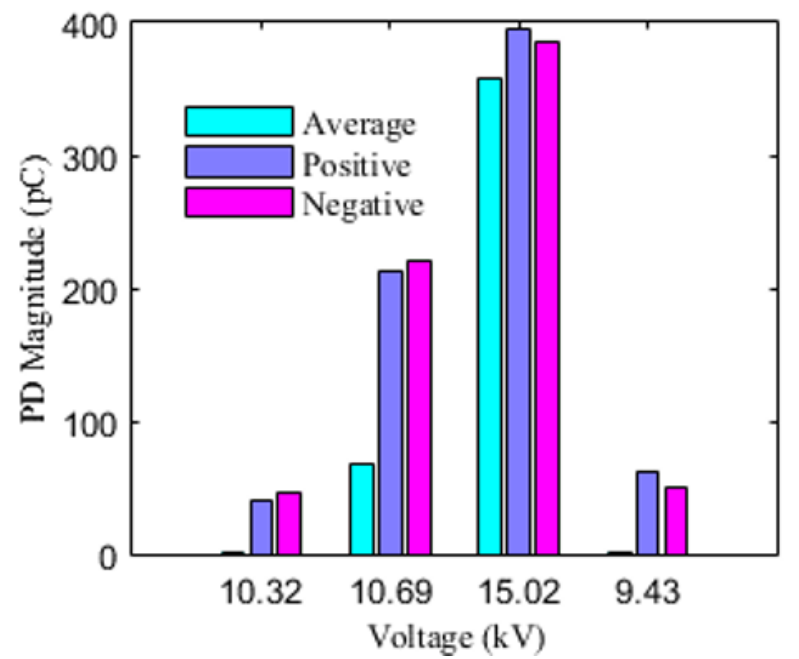

Fig. 5. PD parameters measurement for the aged cable.

\subsection{Isothermal relaxation current}

The curves of the depolarization current, which are measured on the aged and the new samples are shown in Figure 6. It is observed that the value of current increases with the aging time and the whole curve of the depolarization current is offset upward. The aged cable takes more time to decay to zero with 534 seconds as compared to the new one which takes 314 seconds. In accordance with the IRC plot, the maximum value of the I*t and the number of peaks with the time at the maximum peak value are used to assess the aging level of cable insulation [15]. However, other parameters such as cable length and temperature need to be considered. In principle, an increase in temperature leads to a decrease in the maximum peak of the IRC plot. The parameter that appears to be independent of cable length is the time at which a maximum peak occurs and the parameter that practically temperature independent is the A-factor [15]. As shown in Figure 7 both cables have a single peak, and the time of the maximum peak is also lower than 100 seconds which indicates that these cables are in a good condition. Besides, the aging factor for the new cable is 1.08 and for the aged cable is 1.53 which are lower than 1.75 and indicate perfect insulation [16].

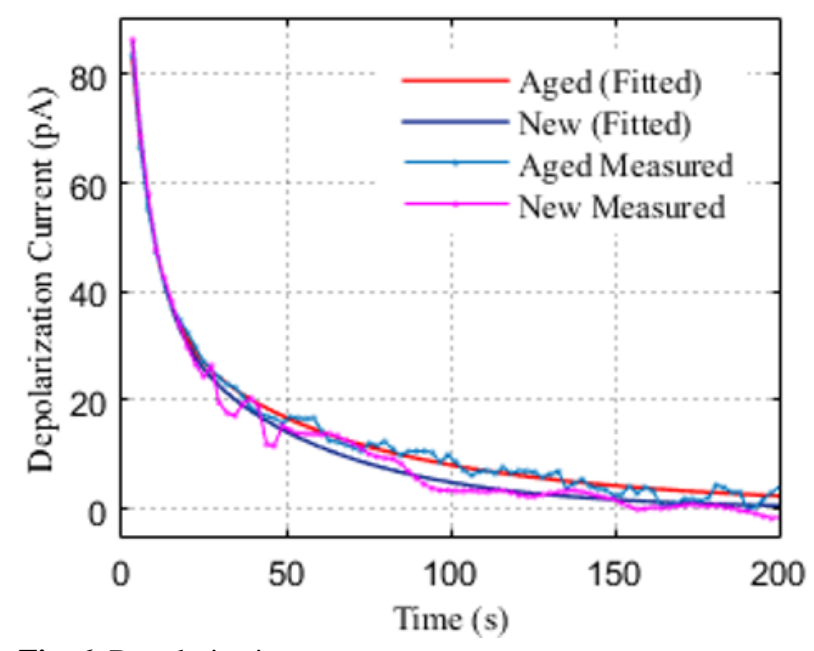

Fig. 6. Depolarization current measurement.

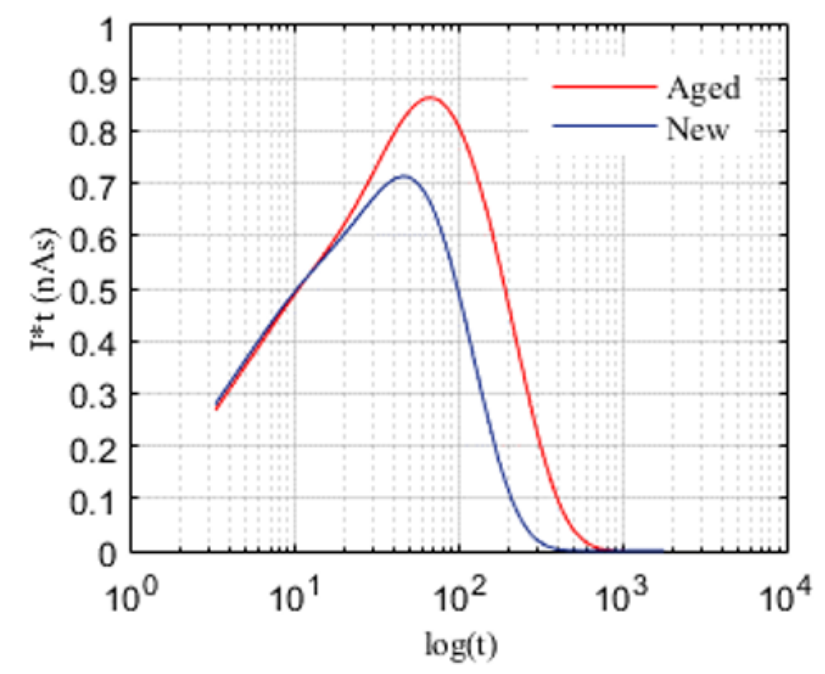

Fig. 7. Approximate IRC plot for the samples.

\section{Conclusion and future work}

In this paper several non-destructive tests were performed to assess the insulation condition for new and aged XLPE cables. The obtained results indicate a good insulation condition for both cables with more aging values/factors for the aged cable. Furthermore, the results show that the dissipation factor value of the insulator increases with the aging time. In addition, it observed that the increase in the frequency and voltage are weakening the insulation.

In future research, more samples under different aging conditions will be investigated to study the correlations between the presented findings in dielectric dissipation factor (DDF) and isothermal relaxation current (IRC).

The authors would like to thank Deanship of scientific research in King Saud University for funding and supporting this research through the initiative of DSR Graduate Students Research Support (GSR). The authors wish to express their thanks for the division of Riyadh Underground Cables in Saudi National Grid Company for their support.

\section{References}

1. W. Wang, S. Li, Y. Tanaka, T. Takada, TDEI, 26, 1757 (2019)

2. A. Das, N. Haque, A. Pradhan, S. Dalai, B. Chatterjee, A. Mukherjee, TDEI, 27, 1814 (2020)

3. Field Testing of Shielded Power Cable Systems Using Very Low Frequency (VLF) (less than $1 \mathrm{~Hz}$ ), IEE Std 400.2 (2013)

4. C. Kocatepe, C. Kumru, R. Ayaz, O. Arkan, H. Akça, EUROCON, 965 (2013)

5. High-Voltage Test Techniques, Partial Discharge Measurements, IEC 60270, 3.1 (2015)

6. X. Zhu, J. Wu, Y. Wang, Y. Yin, TDEI, 27, 455 (2020)

7. E. Haikali, C. Nyamupangedengu, SAIEE, 110, 138139 (2019) 
8. S. Morsalin, B. Phung, IEEE EIM, 36, 27 (2020)

9. K. Zhou, W. Zhao, X. Tao, TDEI, 20, 2141 (2013)

10. S. Morsalin, B. Phung, TDEI, 27, 62 (2020)

11. S. Morsalin, B. Phung, TDEI, 26, 1023 (2019)

12. A. Ponniran, M. Kamarudin, PECON, 42 (2008)

13. R. Probst, H. Putter, F. Petzold, P. Legler, IEEETDS, 2 (2018)
14. IEEE Guide for Partial Discharge Testing of Shielded Power Cable Systems in a Field Environment, IEEE Std 400.3, 13 (2006).

15. B. Oyegoke, F. Foottit, D. Birtwhistle, J. Lyall, P. Wickramasuriya, PESGM, 4 (2006)

16. P. Birkne, TPWRD, 19, 6 (2004) 